\title{
Histone variants: the artists of eukaryotic chromatin
}

\author{
LI Min \& FANG YuDa* \\ National Key Laboratory of Plant Molecular Genetics, Shanghai Institute of Plant Physiology and Ecology, Shanghai Institutes for Biological \\ Sciences, Chinese Academy of Sciences, Shanghai 200032, China \\ Received July 23, 2014; accepted January 23, 2015; published online February 9, 2015
}

\begin{abstract}
The eukaryotic genome is packaged into a complex nucleoprotein structure named chromatin, balancing the compactness of genome and the accessibility of regulatory proteins and RNA polymerases to DNA. The mechanisms of the regulation of chromatin dynamics include the post-translational modification of histones, alteration of nucleosome positions by chromatin remodelers, replacement of canonical histones by histone variants with the aid of histone chaperones, and dynamic organization of the three-dimensional genome in the small nucleus. Histone variants are different from canonical histones by substitution of several amino acid residues or changes in amino acid sequence. Histone variants perform specialized functions such as altering nucleosome stability, dynamics, structure, as well as playing critical roles in a range of biological processes like transcriptional regulation, DNA repair and recombination, development and immune responses. Here we discuss how histone variants, their modification and specific loading to chromatin are involved in transcriptional regulation, DNA repair and plant development.
\end{abstract}

histone variants, histone modification, gene regulation, DNA repair, stress responsiveness

Citation: Li M, Fang YD. Histone variants: the artists of eukaryotic chromatin. Sci China Life Sci, 2015, 58: 232-239, doi: 10.1007/s11427-015-4817-4

In the eukaryotic cell nucleus, the fundamental repeating unit of chromatin is the nucleosome, consisting of $147 \mathrm{bp}$ of DNA left-handedly wrapped around a octameric histone core particle, which contains two copies of each of the four core histone proteins $\mathrm{H} 2 \mathrm{~A}, \mathrm{H} 2 \mathrm{~B}, \mathrm{H} 3$ and $\mathrm{H} 4$, and approximately another 20 bp DNA stretches between the neighbouring core particles coupled with the linker histone H1 $[1,2]$. The huge genomic DNA of eukaryotes is necessary to be densely packed into chromatin to fit within the small dimensions of the nucleus; however, the high order structures restrict the access of transcriptional factors and enzymes to DNA [3]. There are diverse mechanisms involved in breaking through the barriers, including the posttranslational modification of histones, alteration of nucleosome positions by chromatin remodelers and replacement of histone variants. The canonical histones are specifically

*Corresponding author (email: yfang@ sippe.ac.cn) expressed during S-phase and deposited to the genome in a replication-coupled manner. The histone variants, however, are expressed not restricted to S-phase, but throughout the cell cycle, thus the incorporation of histone variants into chromatin is in a replication independent manner [4,5]. In metazoans, the canonical histones are encoded in gene clusters, which encode all four core histones and linker histone $\mathrm{H} 1$, for instance, HIST1, the large clusters of histone genes on human chromosome 6 , contains 55 histone genes. In contrast, the histone variants are outside of gene clusters and encoded by individual genes [5,6]. In Arabidopsis, however, both the canonical histones and variants are not encoded by gene clusters, for example, there are 15 histone H3 genes in Arabidopsis genome: AT1g09200, AT3g27360, AT5g-10390, AT5g10400 and AT5g65360, which encode the canonical histone H3.1; AT4g40030, AT4g40040, AT5g-10980 and AT1g13370, AT1g19890, AT1g75600, AT1g-75610, AT5g12910, encoding H3.3 or H3.3-like his- 
tone variants [7]. These genes disperse in different chromosome positions. The histone variants can exchange the canonical histones and then form an architecturally divergent sub- chromatin domains for specific biological functions [8].

In addition to the canonical histones, the unstructured $\mathrm{N}$-termini and the histone fold domains of histone variants are also subjected to a set of post-translational modifications (PTMs), including phosphorylation, acetylation, methylation and ubiquination. These modifications have important roles in regulating chromatin dynamics during diverse processes, such as DNA replication, transcription and DNA repair $[9,10]$.

Here, we discuss the roles of histone variants and their PTMs in regulating gene expression, DNA repair, especially in DNA double strand break (DSB) repair pathway, and summarize their functions in plant development.

\section{The universality of histone variants}

Until now, histone variants have been identified in all core histones except histone $\mathrm{H} 4$. With increasing number of the known histone variants in recent years, the naming convention was established in 2012, which based on historical usage along with phylogenetic relationship [11], the nomenclature normalized the field and provided the convenience for database search. Histone $\mathrm{H} 2 \mathrm{~A}$ family has the largest number of variants, including H2A.X and H2A.Z evolutionarily conserved from yeast to mammals [12,13], macroH2A and $\mathrm{H} 2 \mathrm{~A} . \mathrm{Bbd}$ found only in mammals $[5,14]$ and H2A.W specific to plant [11]. H2A.W shows approximately $50 \%$ amino acid sequence identity with canonical $\mathrm{H} 2 \mathrm{~A}$, and contains a SPKK motif at its C-terminal region, which can bind to DNA minor groove $[15,16]$, and the C-terminal motif is responsible for the heterochromatin condensation in vivo and vitro, therefore, $\mathrm{H} 2 \mathrm{~A}$.W is a heterochromatin-specific histone $\mathrm{H} 2 \mathrm{~A}$ variant [17]. H2A.Z is the most conserved variant in the H2A family $[13,18]$, which differs from the canonical $\mathrm{H} 2 \mathrm{~A}$ at many amino acid positions throughout the full length sequence [19]. In contrast, H2A.X differs mainly in the carboxyl terminal, which contains a conserved SQ motif [20-22]. H2A.Z is involved in many biological processes, including transcriptional regulation, genome stability and the formation of heterochromatin boundaries [23]. H2A.Z preferentially occupies few nucleosomes around the transcription start sites (TSSs) of genes, which is conserved in yeast, Drosophila, plants and mammals [24-28]. The interaction between H2A.Z/H2B dimmer and $\mathrm{H} 3 / \mathrm{H} 4$ tetramer is less stable than the $\mathrm{H} 2 \mathrm{~A} / \mathrm{H} 2 \mathrm{~B}$ [29]. H2A.Z is incorporated into chromatin by a conserved complex termed SWR1 in yeast and SRCAP in mammals [30-32]. The SWR-like complex has also been found in Arabidopsis, which contains ARP6, PIE1 and SEF [33-35].
There are two $\mathrm{H} 3$ variants found in all eukaryotes: H3.3 and CenH3. H3.3 differs from H3.1 only in 4- or 5- amino acid positions. In Arabidopsis, the amino acid residues at positions 31, 41, 87 and 90 of H3.3 define its difference from H3.1 [36]. In Drosophila, the difference between H3.3 and H3.1 is defined by the sites of 31, 87, 89 and 90 [37]; however, in human, there are 5-aa residues of $\mathrm{H} 3.3$ different from H3.1, which are 31, 87, 89, 90 and 96 [38]. In Arabidopsis, a recent study has revealed that four amino acids guide the nucleosome assembly and disassembly: the amino acid residues 87 and 90 of $\mathrm{H} 3.3$ are critical for its deposition into rDNAs especially the site of 87 , and amino acid residues 31 and 41 guide the disassembly of H3.3-containing nucleosomes [36]. The deposition of H3.3 into chromatin is mediated by H3.3 specific histone chaperones: HIRA, responsible for replication-independent $\mathrm{H} 3.3$ deposition at actively transcribed regions, DAXX-ATRX complex and DEK, mediating H3.3 incorporation at regulatory regions and heterochromatin respectively [39-41].

Centromere-specific histone $\mathrm{H} 3$ variant $\mathrm{CenH} 3$ is incorporated at centromeres and critical for centromeric functions. Sequence analysis revealed that CenH3 shares a similar $\mathrm{C}$ terminal histone fold domain to canonical histone $\mathrm{H} 3$, but there are replacements of amino acids in histone fold domain regions supposed to mediate the targeting to the centromeres [42]. In addition, the $\mathrm{N}$ terminal tail is hypervariable with CenH3 having a long $\mathrm{N}$ terminal tail which is not alignable to the canonical H3 $[43,44]$, and the $\mathrm{N}$ terminal tail is essential for the correct localization of $\mathrm{CenH} 3$ during meiosis, which is critical for chromosome inheritance $[45,46]$. Interestingly, the haploid Arabidopsis plants were generated by CenH3-mediated genome elimination [47], which is a useful tool in molecular breeding [48,49]. CenH3 was given diverse names in different organisms, for example, Cna1 in Tetrahymena thermophlia [50], Cse4 in Saccharomyces cerevisiae [51], HCP-1 in Caenorhabditis elegans [52], CENP-A in humans [53] and HTR12 in Arabidopsis thaliana [54]. HJURP is believed to assemble CenH3 into centromeric chromatin [55]; its timely phosphorylation by cyclin-dependent kinases and proper localization to DNA are essential for CenH3 loading [56].

Compared to the core histones, linker histone $\mathrm{H} 1$ and its variants are less conserved in sequence and structure. FRAP experiments revealed the highly dynamic binding to chromatin in vivo, which might be important for regulating the genome functions $[57,58]$. Studies in unicellular eukaryotes have shown the roles of $\mathrm{H} 1$ in development, transcriptional regulation and the recombination at rDNA locus [59-61]. In contrast, high eukaryotes have multiple variants of linker histone $\mathrm{H} 1$, which function in nucleosome spacing in chicken cells [62] as well as in mouse cells and embryonic development in mice [63]. In Arabidopsis, histone H1 contributes to DNA methylation and gene imprinting [64,65].

In addition to the above mentioned universal functions of histone variants, histone variants are also involved in spe- 
cialised functions, such as that for the sperm specific histones. In Arabidopsis, which has double fertilization during sexual reproduction, the H3.3 variant AT1g19890 is specifically expressed in male gametes. Live imaging revealed the replication-independent dynamics of $\mathrm{H} 3.3$ in the zygote and replication-dependent manner in the endosperm [66]. During gametogenesis, CenH3 could be observed on sperm chromatin but not the zygotic chromatin [67]. In mammals, the first zygotic divisions are also marked by replication independent dynamics of H3.3 [68,69]. In addition, H2B variant TH2B played a key role in genome-wide chromatin transition from histone to protamine and protamine to histone [70], indicating the important functions of histone variants in gametogensis.

The histone variants change the structure, dynamics and stability of nucleosomes in order to facilitate gene activation or inactivation. In the following section, we will focus on the specific loading of histone variants to the genome and their functions in transcriptional regulation and DNA repair, especially histone variants H2A.Z, H3.3 and H2AX.

\section{Roles of histone variants in transcriptional regulation}

\section{$2.1 \quad$ H2A.Z}

As early as 30 years ago, the role of H2A.Z in transcriptional regulation had been indicated in Tetrahymena thermophila, H2A.Z was specific to transcriptionally active macronucleus and absent from the inactive micronucleus, suggesting that H2A.Z plays an active role in genes regulation [71]. Then, the studies in yeast revealed that H2A.Z had effect on the transcriptional regulation and partially redundant with nucleosome remodelling complex SWI/SNF and Gcn-5 containing complex [72]. In addition, H2A.Z facilitates the recruitment of RNA polymerase II (RNP II) in certain genes under specific conditions [73], antagonizes telomeric silencing, which acts as a boundary element to protect euchromatin [74]. In human cells, CHIP-chip (chromatin immunoprecipitation-chip) experiments indicated that the correlation between H2A.Z and RNP II, H2A.Z is dynamically recruited to promoters before RNP II loading, suggesting its roles in transcription activation [75]. In addition, there were evidences showing the function of H2A.Z in transcription elongation in Drosophila [76] .

Apart from the function of $\mathrm{H} 2 \mathrm{~A} . \mathrm{Z}$ in positively regulating gene expression, H2A.Z also plays a role in negatively regulating gene expression in Drosophila [77], S. cerevisiae [78] and human [79]. In yeast, H2A.Z may favor to stabilize the binding of the Sir complex to nucleosomes at HMR locus to mediate the silencing of HMR [78]. In mammals, H2A.Z directly interacts with HP1- $\alpha$ and works together to regulate the formation of heterochromatin domains [79].

Identification of the occupation of histone variants within genome helps us to understand their functions. The global views of the distribution of H2A.Z have been reported in many organisms, including yeast, Drosophila, Arabidopsis and human. In yeast, H2A.Z preferentially locates to the promoters of inactive genes. H2A.Z may also play a role in nucleosome positioning, for example, at the GAL4 model gene, H2A.Z-containing promoters define positions of nucleosomes in wild type, and H2A.Z-free promoters have a less organized chromatin structure in H2A.Z-null cells [24]. In Drosophila, the distribution of H2A.Z is not uniform, widely within the euchromatin and heterochromatin [80]. H2A.Z enrichment at $5^{\prime}$ regions of genes has been observed in many organisms, including yeast, Drosophila, human and plants, which affects the nucleosome density and the accessibility to DNA templates $[26,27,81,82]$, suggesting that H2A.Z may contribute to form unique chromatin domains for transcription activation at TSSs [83]. H2A.Z in Arabidopsis was found to locate at gene bodies [27], implying its relation to gene responsiveness [84]. However, the mechanism of the role of $\mathrm{H} 2 \mathrm{~A} . \mathrm{Z}$ in gene regulation remains largely unknown.

\section{$2.2 \quad H 3.3$}

The genome-wide distributions of $\mathrm{H} 3.3$ have been well understood in many organisms. In yeast, histone H3/H3.1 is more enriched at the promoter regions than coding regions and the positions at promoters are associated with transcriptional activity $[85,86]$. In contrast, H3.3 distributes not only at regions with transcriptional activity, but also at transposons in Drosophila [87]. Similar to mammals, the genome mapping of Arabidopsis H3.3 revealed that H3.3 is deposited at regions with transcriptional activity and is predominantly enriched at $3^{\prime}$ end of genes [88]. Recently, the genome-wide characterization of $\mathrm{H} 3.3$ in mammals revealed that $\mathrm{H} 3.3$ replaces the canonical $\mathrm{H} 3$ at gene bodies, ciselements including promoters, enhancers and polycomb response elements, as well as telomeres and pericentromeric heterochromatin at different turnover rates, suggesting that there are different mechanisms involved to control the H3.3 replacement. Notably, the fast turnover rate of H3.3 at promoters is positively correlated with active histone modifications such as methylation of $\mathrm{H} 3 \mathrm{~K} 4$, acetylation of $\mathrm{H} 3 \mathrm{~K} 9$ and H3K27, and also associated with H2A.Z, which is responsible for both gene activity and inactivity [89].

The studies on the genome-wide distributions of histone variants indicated the functions of histone variants in transcriptional regulation; however, the molecular mechanisms involved are still mysteries. Histone variants may work via chromatin level such as modulating the high structure of chromatin, or cooperate with regulatory protein complexes to regulate gene expression.

\section{Roles of histone variants in DNA repair}

Due to the endogenous and exogenous DNA damage agents, 
DNA damage occurs frequently in cells. In response to DNA damage, cells activate multiple processes, including gene regulation, cell cycle regulation, apoptosis and DNA repair. In the following section, we will focus on the role of histone variants H2A.X, H2A.Z as well as their modifications in DNA repair, especially in the double strand break (DSB) repair.

\subsection{H2A.X}

In the past few decades, many studies have contributed to revealing the molecular mechanism of DNA damage response (DDR) pathways, and H2A.X was found to be an important component of DDR. In response to DNA double strand break (DSB), H2A.X is rapidly phosphorylated at serine 139 in animals or serine 129 in yeast by a set of PI3-K-like kinases, including DNA-PK, ATM and ATR [90-93], the phosphorylated H2A.X was known as $\gamma$-H2A.X. In the presence of DNA DSB, $\gamma$-H2A.X rapidly accumulates around the DSB lesion, and other DNA damage response and repair related proteins also concentrate around the sites of DSBs; however, many of these actions are dependent on $\gamma-\mathrm{H} 2 \mathrm{~A}$.X. For instance, $\gamma-\mathrm{H} 2 \mathrm{~A}$.X interacts directly with MDC1 (mediator of damage checkpoint protein) [94], a mediator to recruit the MNR complex, including RAD51, MRE11, NBS1 (Nijmegen Breakage Syndrome 1) $[95,96]$. MDC1 stimulates ATM kinase activity and ATM further phosphorylate H2A.X, resulting in the spreading of $\gamma-\mathrm{H} 2 \mathrm{~A} . \mathrm{X}$ around the DBSs [97]. In addition, the accumulations of other components of the repair machinery like Rad51, 53BP1 (p53-binding protein), BRCA1 (breast and ovarian cancer susceptibility protein 1) also rely on $\gamma$-H2A.X. Thus, $\gamma-\mathrm{H} 2 \mathrm{~A}$.X is not simply a rapid and sensitive marker for DSBs in DDR, but an amplifier for the DNA damage signals. Upon damage, $\gamma-\mathrm{H} 2 \mathrm{~A} . \mathrm{X}$ not only recruits the DNA damage repair proteins, but also the chromatin remodelers such as INO80. The mutated INO80 complex in yeast is hypersensitive to DNA damage agents [98], and impaired for the eviction of H2A.Z and $\gamma$-H2A.X, indicating that the chromatin remodelling driven by the INO80 is involved in DNA repair [99]. In addition to the phosphorylation of H2A.X which is required for DNA damage repair, recent studies have revealed that H2A.X ubiquitylation and acetylation are also involved in DDR [100].

During the DNA repair process, $\gamma$-H2A.X foci will gradually diminish [101]; however, how $\gamma$-H2A.X removes from the chromatin remains to be discovered. Research has indicated that there are multiple players involved in eliminating $\gamma$-H2A.X. In budding-yeast, $\gamma$-H2A.X is removed from chromatin before its dephosphorylation which is mediated by a three-protein complex named HTP-C containing the phosphatase Pph3 that regulates the phosphorylation status of H2A.X in vivo [102]. In animals, however, protein phosphatase $2 \mathrm{~A}(\mathrm{PP} 2 \mathrm{~A})$ is responsible for the dephosphorylation of $\gamma$-H2A.X. When PP2A is inhibited, the $\gamma$-H2A.X foci always exists and the cells are hypersensitive to DNA damage [103]. In addition, there are many remodelling complexes involved in histone eviction, exchange and nucleosome reassembly in order to remove $\gamma-\mathrm{H} 2 \mathrm{~A}$.X. For instance, the INO80 in yeast and NBS1 in mammals were found to have a function in histone eviction at DSBs [104,105]. Besides, the FACT, a heterodimer of Spt16 and SSRP1, has been reported to be involved in the replacement of nucleosomal H2A.X with H2A in human cells [106].

Without doubt, H2A.X is a key player in DNA repair, however, mild defects of DNA damage repair were observed in the H2A.X-deficient cells or animals, indicating that there are H2A.X-independent mechanisms in DDR.

\subsection{H2A.Z}

In addition to the role of $\mathrm{H} 2 \mathrm{~A} . \mathrm{X}$ in DNA repair, recent work has made a breakthrough in discovering the role of H2A.Z in DSB repair. CHIP at a defined DSB site showed that H2A.Z functions directly in DSB, rather than by an indirect way through altered gene expression [107]. An open chromatin structure is critical to DNA repair process, enabling the repair machinery to access to the DNA damage sites, and the chromatin remodelling complex NvA4 is responsible for this process. NvA4 consists of two subunits-the p400 motor ATPase, which belongs to the INO80 family [108] and Tip60 acetyltransferase, which functions in acetylating the histone H2A and H4 [109]. The deposition of H2A.Z into nucleosomes at DSBs by p400 motor ATPase creates an open, accessible chromatin domain, which facilitates the acetylation and ubiquitination of histones, these modifications are required for altering the chromatin conformation and DSB repair [110]. GFP-HR (homologous recombination) reporter system indicated that loss of H2A.Z exchange leads to defect of the HR repair pathway [111]. In the H2A.Z and p400 inactive cells, the level of NHEJ (nonhomologous end-joining) significantly decreased [107]. These results suggested that H2A.Z participates in DNA repair pathway; however, the mechanism in detail remains to be discovered.

\section{Histone variants in plants}

Compared to mammals, plants continually face the changes of environments like temperature, drought, nutrition as well as pathogens, and have developed multiple mechanisms to overcome the changeable environmental conditions to adapt their developments. Here we summarize and discuss the roles of histone variants in regulating gene expression in response to developmental and environmental stimuli.

\subsection{H2A.Z in Arabidopsis}

Recent studies have suggested that H2A.Z and H3K4 meth- 
ylation are involved in regulation of gene responsiveness [112]. For instance, in yeast ino 80 mutant, H2A.Z mislocalization results in the reduced responsiveness to transcriptional changes of gene KAR4 [113]. Arabidopsis H2A.Z not only enriches at TSSs which is in agreement with results from yeast and human, but also locates at gene bodies of genes that respond to environmental or developmental stimuli.

In a forward genetic screen, ARP6, a gene which encodes a critical subunit of SWR1 complex known to deposit H2A.Z, was found to control responses to ambient temperature in Arabidopsis [114]. Gene expression profiling revealed a significant constitutive warm temperature transcriptome in arp6 mutants which defect in H2A.Z distribution. CHIP indicated that H2A.Z occupancy at TSSs of temperature responsive genes was reduced at $27^{\circ} \mathrm{C}$ compared to that at $17^{\circ} \mathrm{C}$ in wild type, suggesting that H2A.Z-containing nucleosomes perform dynamic responses to temperature [114]. Phosphate starvation response (PSR) genes, which always have H2A.Z-containing nucleosomes near their TSSs, show low expression in wild type at normal condition and are induced under phosphate deficiency. In contrast, PSR genes were highly induced in arp6 mutants at the normal condition and showed phosphate starvation related phenotypes, indicating H2A.Z plays a role in maintaining the repressive state of the PSR [115]. Similarly, mutation in PIE, which codes a subunit of SWR complex, showed a constitutive induction of systemic acquired resistance (SAR) dependent genes in the absence of pathogen infection [116]. These data suggested that H2A.Z coupled with SWR plays repressive or inductive roles in Arabidopsis. In addition, H2A.Z occupancy at gene bodies has been reported to correlate with gene responsiveness [84]. However, the mechanisms of H2A.Z in the regulation of gene responsiveness remain unclear.

Arabidopsis H2A.Z also contributes to transcriptional regulation. For example, the FLC gene expresses during vegetative growth and stays silent before flowering, which is critical in the transition from the vegetative growth to flowing. This switch from the active to silent state is associated with various regulations at chromatin level, including the modification of histone $\mathrm{H} 3$, chromatin remodelling, deposition of histone H2A.Z and ubiquitination of histone H2B [117-120]. H2A.Z is deposited at the FLC locus, and loss of H2A.Z leads to reduced FLC expression and promoted flowering, indicating that $\mathrm{H} 2 \mathrm{~A} . \mathrm{Z}$ positively regulates FLC to repress flowering [116].

Mutants in H2A.Z and SWR1 subunits exhibit many developmental phenotypes, including early flowering, small flowers, dwarf, curly leaves and reduced fertility [121]. Not surprisingly, both the male and female gametophyte developments are disturbed in these mutants. The mutants have a smaller size of anthers and less number of pollen grains resulting from the defect in male gametogenesis. Defects in female meiosis were also observed in the arp6 mutant as a result from downregulation of meiotic genes, such as DMC1 (disrupted meiotic cDNA1). H2A.Z is deposited in the DMC1 gene body in wild type; however, in the arp6 mutant, the occupancy of H2A.Z is significantly decreased at $\mathrm{DMC} 1$ gene body, supporting a role of $\mathrm{H} 2 \mathrm{~A} . \mathrm{Z}$ in meiosis [122].

\subsection{H3.3 in Arabidopsis}

H3.3 is less understood in Arabidopsis than animals. Recently, genome-wide location maps of the Arabidopsis H3.3 revealed that $\mathrm{H} 3.3$ is distributed at gene bodies which correlate with transcriptional activity of related genes, promoter regions and the downstream of the $3^{\prime}$ end of active genes, suggesting a role of H3.3 in transcriptional regulation [123].

\section{Perspective}

Over the past few years, evidences have indicated the roles of histone variants in transcriptional regulation, DNA repair and plant development. The replacement of canonical histones by variants results in the alteration of nucleosome dynamics, stability, structure and the accessibility to DNA templates by transcription factors or enzymes like Pol II. In addition to histone variant replacement, transcriptional regulation at the chromatin level is frequently involved in histone variant-specific modifications; however, whether there are relationships between histone variant replacement and modifications in gene regulation is rarely reported. Moreover, DNA methylation coupled with histone variants in gene activation and inactivation is required for future investigation. The mechanisms for the roles of histone variants in DNA damage and plant development are also required for intensive studies.

This work was supported by the National Natural Science Foundation of China (31171168 and 91319304) and National Basic Research Program of China (2012CB910503).

1 Khorasanizadeh S. The nucleosome: from genomic organization to genomic regulation. Cell, 2004, 116: 259-272

2 Luger K, Mader AW, Richmond RK, Sargent DF, Richmond TJ. Crystal structure of the nucleosome core particle at $2.8 \AA$ resolution. Nature, 1997, 389: 251-260

$3 \mathrm{Li}$ B, Carey M, Workman JL. The role of chromatin during transcription. Cell, 2007, 128: 707-719

4 Talbert PB, Henikoff S. Histone variants-ancient wrap artists of the epigenome. Nat Rev Mol Cell Biol, 2010, 11: 264-275

5 Malik HS, Henikoff S. Phylogenomics of the nucleosome. Nat Struct Biol, 2003, 10: 882-891

6 Marzluff WF, Gongidi P, Woods KR, Jin J, Maltais LJ. The human and mouse replication-dependent histone genes. Genomics, 2002, 80: 487-498

7 Okada T, Endo M, Singh MB, Bhalla PL. Analysis of the histone H3 gene family in Arabidopsis and identification of the malegamete-specific variant AtMGH3. Plant J, 2005, 44: 557-568

8 Henikoff S, Furuyama T, Ahmad K. Histone variants, nucleosome 
assembly and epigenetic inheritance. Trends Genet, 2004, 20: 320-326

9 Jenuwein T, Allis CD. Translating the histone code. Science, 2001, 293: 1074-1080

10 Escargueil AE, Soares DG, Salvador M, Larsen AK, Henriques JAP. What histone code for DNA repair? Mutat Res Rev Mut Res, 2008, 658: $259-270$

11 Talbert PB, Ahmad K, Almouzni G, Ausio J, Berger F, Bhalla PL, Bonner WM, Cande WZ, Chadwick BP, Chan SWL, Cross GAM, Cui LW, Dimitrov SI, Doenecke D, Eirin-Lopez JM, Gorovsky MA, Hake SB, Hamkalo BA, Holec S, Jacobsen SE, Kamieniarz K, Khochbin S, Ladurner AG, Landsman D, Latham JA, Loppin B, Malik HS, Marzluff WF, Pehrson JR, Postberg J, Schneider R, Singh MB, Smith MM, Thompson E, Torres-Padilla ME, Tremethick DJ, Turner BM, Waterborg JH, Wollmann H, Yelagandula R, Zhu B, Henikoff S. A unified phylogeny-based nomenclature for histone variants. Epigenet Chromat, 2012, 5: 1756-8935

12 Wu RS, Nishioka D, Bonner WM. Differential conservation of histone $2 \mathrm{~A}$ variants between mammals and sea urchins. J Cell Biol, 1982, 93: 426-431

13 Thatcher TH, Gorovsky MA. Phylogenetic analysis of the core histones H2A, H2B, H3, and H4. Nucleic Acids Res, 1994, 22: 174-179

14 Bernstein E, Hake SB. The nucleosome: a little variation goes a long way. Biochem Cell Biol, 2006, 84: 505-517

15 Lindsey GG, Orgeig S, Thompson P, Davies N, Maeder DL. Extended C-terminal tail of wheat histone H2A interacts with DNA of the "linker" region. J Mol Biol, 1991, 218: 805-813

16 Huh GH, Matsuura Y, Meshi T, Iwabuchi M. Differential expression of the two types of histone H2A genes in wheat. Biochim Biophys Acta, 1995, 1261: 155-160

17 Yelagandula R, Stroud H, Holec S, Zhou K, Feng SH, Zhong XH, Muthurajan UM, Nie X, Kawashima T, Groth M, Luger K, Jacobsen SE, Berger F. The histone variant H2A.W defines heterochromatin and promotes chromatin condensation in Arabidopsis. Cell, 2014, 158: $98-109$

18 van Daal A, White EM, Elgin SC, Gorovsky MA. Conservation of intron position indicates separation of major and variant $\mathrm{H} 2 \mathrm{As}$ is an early event in the evolution of eukaryotes. J Mol Evol, 1990, 30: $449-455$

19 Suto RK, Clarkson MJ, Tremethick DJ, Luger K. Crystal structure of a nucleosome core particle containing the variant histone H2A.Z. Nat Struct Biol, 2000, 7: 1121-1124

20 Redon C, Pilch D, Rogakou E, Sedelnikova O, Newrock K, Bonner W. Histone H2A variants H2AX and H2AZ. Curr Opin Genet Dev, 2002, 12: 162-169

21 Mannironi C, Bonner WM, Hatch CL. H2A.X. a histone isoprotein with a conserved C-terminal sequence, is encoded by a novel mRNA with both DNA replication type and polyA $3^{\prime}$ processing signals. Nucleic Acids Res, 1989, 17: 9113-9126

22 van Attikum H, Gasser SM. Crosstalk between histone modifications during the DNA damage response. Trends Cell Biol, 2009, 19: 207-217

23 Raisner RM, Madhani HD. Patterning chromatin: form and function for H2A.Z variant nucleosomes. Curr Opin Genet Dev, 2006, 16: $119-124$

24 Guillemette B, Bataille AR, Gevry N, Adam M, Blanchette M, Robert F, Gaudreau L. Variant histone H2A.Z is globally localized to the promoters of inactive yeast genes and regulates nucleosome positioning. PLoS Biol, 2005, 3: 2100-2110

25 Li B, Pattenden SG, Lee D, Gutierrez J, Chen J, Seidel C, Gerton J, Workman JL. Preferential occupancy of histone variant H2AZ at inactive promoters influences local histone modifications and chromatin remodeling. Proc Natl Acad Sci USA, 2005, 102: 18385-18390

26 Mavrich TN, Jiang CZ, Ioshikhes IP, Li XY, Venters BJ, Zanton SJ, Tomsho LP, Qi J, Glaser RL, Schuster SC, Gilmour DS, Albert I, Pugh BF. Nucleosome organization in the Drosophila genome. Nature, 2008, 453: 358-362

27 Zilberman D, Coleman-Derr D, Ballinger T, Henikoff S. Histone
H2A.Z and DNA methylation are mutually antagonistic chromatin marks. Nature, 2008, 456: 125-129

28 Coleman-Derr D, Zilberman D. DNA methylation, H2A.Z, and the regulation of constitutive expression. Cold Spring Harb Symp Quant Biol, 2012, 77: 147-154

29 Suto RK, Clarkson MJ, Tremethick DJ, Luger K. Crystal structure of a nucleosome core particle containing the variant histone H2A.Z. Nat Struct Biol, 2000, 7: 1121-1124

30 Krogan NJ, Keogh MC, Datta N, Sawa C, Ryan OW, Ding H, Haw RA, Pootoolal J, Tong A, Canadien V, Richards DP, Wu X, Emili A, Hughes TR, Buratowski S, Greenblatt JF. A Snf2 family ATPase complex required for recruitment of the histone H2A variant Htz1. Mol Cell, 2003, 12: 1565-1576

31 Cai Y, Jin JJ, Florens L, Swanson SK, Kusch T, Li B, Workman JL, Washburn MP, Conaway RC, Conaway JW. The mammalian YL1 protein is a shared subunit of the TRRAP/TIP60 histone acetyltransferase and SRCAP complexes. J Biol Chem, 2005, 280: 13665-13670

32 Mizuguchi G, Shen XT, Landry J, Wu WH, Sen S, Wu C. ATPdriven exchange of histone H2AZ variant catalyzed by SWR1 chromatin remodeling complex. Science, 2004, 303: 343-348

33 Martin-Trillo M, Larazo A, Poethig RS, Gomez-Mena C, Pineiro MA, Martinez-Zapater JM, Jarillo JA. EARLY IN SHORT DAYS 1 (ESD1) encodes ACTIN-RELATED PROTEIN 6 (AtARP6), a putative component of chromatin remodelling complexes that positively regulates FLC accumulation in Arabidopsis. Development, 2006, 133: 1241-1252

34 Noh YS, Amasino RM. PIE1, an ISWI family gene, is required for FLC activation and floral repression in Arabidopsis. Plant Cell, 2003, 15: $1671-1682$

35 March-Diaz R, Garcia-Dominguez M, Florencio FJ, Reyes JC. SEF, a new protein required for flowering repression in Arabidopsis, interacts with PIE1 and ARP6. Plant Physiol, 2007, 143: 893-901

36 Shi L, Wang J, Hong F, Spector DL, Fang Y. Four amino acids guide the assembly or disassembly of Arabidopsis histone H3.3-containing nucleosomes. Proc Natl Acad Sci USA, 2011, 108: 10574-10578

37 Ahmad K, Henikoff S. Histone H3 variants specify modes of chromatin assembly. Proc Natl Acad Sci USA, 2002, 99: 16477-16484

38 Gendler K, Paulsen T, Napoli C. ChromDB: The chromatin database. Nucleic Acids Res, 2008, 36: D298-302

39 Bonnefoy E, Orsi GA, Couble P, Loppin B. The essential role of Drosophila HIRA for de novo assembly of paternal chromatin at fertilization. PLoS Genet, 2007, 3: 1991-2006

40 Sawatsubashi S, Murata T, Lim J, Fujiki R, Ito S, Suzuki E, Tanabe M, Zhao Y, Kimura S, Fujiyama S, Ueda T, Umetsu D, Ito T, Takeyama K, Kato S. A histone chaperone, DEK, transcriptionally coactivates a nuclear receptor. Genes Dev, 2010, 24: 159-170

41 Goldberg AD, Banaszynski LA, Noh KM, Lewis PW, Elsaesser SJ, Stadler S, Dewell S, Law M, Guo XY, Li X, Wen DC, Chapgier A, DeKelver RC, Miller JC, Lee YL, Boydston EA, Holmes MC, Gregory PD, Greally JM, Rafii S, Yang CW, Scambler PJ, Garrick D, Gibbons RJ, Higgs DR, Cristea IM, Urnov FD, Zheng DY, Allis CD. Distinct factors control histone variant $\mathrm{H} 3.3$ localization at specific genomic regions. Cell, 2010, 140: 678-691

42 Sullivan KF, Hechenberger M, Masri K. Human CENP-A contains a histone $\mathrm{H} 3$ related histone fold domain that is required for targeting to the centromere. J Cell Biol, 1994, 127: 581-592

43 Malik HS, Henikoff S. Adaptive evolution of Cid, a centromerespecific histone in Drosophila. Genetics, 2001, 157: 1293-1298

44 Talbert PB, Masuelli R, Tyagi AP, Comai L, Henikoff S. Centromeric localization and adaptive evolution of an Arabidopsis histone H3 variant. Plant Cell, 2002, 14: 1053-1066

45 Ravi M, Shibata F, Ramahi JS, Nagaki K, Chen CB, Murata M, Chan SWL. Meiosis-specific loading of the centromere-specific histone CENH3 in Arabidopsis thaliana. PLoS Genet, 2011, 7: e1002121

46 Ravi M, Kwong PN, Menorca RMG, Valencia JT, Ramahi JS, Stewart JL, Tran RK, Sundaresan V, Comai L, Chan SWL. The rapidly evolving centromere-specific histone has stringent functional requirements in Arabidopsis thaliana. Genetics, 2010, 186: 461-471 
47 Ravi M, Chan SWL. Haploid plants produced by centromeremediated genome elimination. Nature, 2010, 464: 615-618

48 Seymour DK, Filiault DL, Henry IM, Monson-Miller J, Ravi M, Pang AD, Comai L, Chan SWL, Maloof JN. Rapid creation of Arabidopsis doubled haploid lines for quantitative trait locus mapping. Proc Natl Acad Sci USA, 2012, 109: 4227-4232

49 Wijnker E, van Dun K, de Snoo CB, Lelivelt CLC, Keurentjes JJB, Naharudin NS, Ravi M, Chan SWL, de Jong H, Dirks R. Reverse breeding in Arabidopsis thaliana generates homozygous parental lines from a heterozygous plant. Nat Genet, 2012, 44: 467-470

50 Cui B, Liu Y, Gorovsky MA. Deposition and function of histone H3 variants in Tetrahymena thermophila. Mol Cell Biol, 2006, 26: 7719-7730

51 Stoler S, Keith KC, Curnick KE, Fitzgerald-Hayes M. A mutation in CSE4, an essential gene encoding a novel chromatin-associated protein in yeast, causes chromosome nondisjunction and cell cycle arrest at mitosis. Genes Dev, 1995, 9: 573-586

52 Moore LL, Morrison M, Roth MB. HCP-1, a protein involved in chromosome segregation, is localized to the centromere of mitotic chromosomes in Caenorhabditis elegans. J Cell Biol, 1999, 147: $471-480$

53 Earnshaw WC, Rothfield N. Identification of a family of human centromere proteins using autoimmune sera from patients with scleroderma. Chromosoma, 1985, 91: 313-321

54 Fang Y, Spector DL. Centromere positioning and dynamics in living Arabidopsis plants. Mol Biol Cell, 2005, 16: 5710-5718

55 Shuaib M, Ouararhni K, Dimitrov S, Hamiche A. HJURP binds CENP-A via a highly conserved N-terminal domain and mediates its deposition at centromeres. Proc Natl Acad Sci USA, 2010, 107: 1349-1354

56 Muller S, de Oca RM, Lacoste N, Dingli F, Loew D, Almouzni G. Phosphorylation and DNA binding of HJURP determine its centromeric recruitment and function in CenH3 (CENP-A) loading. Cell Rep, 2014, 8: 190-203

57 Lever MA, Th'ng JPH, Sun XJ, Hendzel MJ. Rapid exchange of histone H1.1 on chromatin in living human cells. Nature, 2000, 408: $873-876$

58 Misteli T, Gunjan A, Hock R, Bustin M, Brown DT. Dynamic binding of histone $\mathrm{H} 1$ to chromatin in living cells. Nature, 2000, 408: $877-881$

59 Ushinsky SC, Bussey H, Ahmed AA, Wang Y, Friesen J, Williams BA, Storms RK. Histone H1 in Saccharomyces cerevisiae. Yeast, 1997, 13: 151-161

60 Patterton HG, Landel CC, Landsman D, Peterson CL, Simpson RT. The biochemical and phenotypic characterization of Hholp, the putative linker histone $\mathrm{H} 1$ of Saccharomyces cerevisiae. J Biol Chem, 1998, 273: 7268-7276

61 Li CH, Mueller JE, Elfline M, Bryk M. Linker histone H1 represses recombination at the ribosomal DNA locus in the budding yeast Saccharomyces cerevisiae. Mol Microbiol, 2008, 67: 906-919

62 Hashimoto H, Takami Y, Sonoda E, Iwasaki T, Iwano H, Tachibana M, Takeda S, Nakayama T, Kimura H, Shinkai Y. Histone H1 null vertebrate cells exhibit altered nucleosome architecture. Nucleic Acids Res, 2010, 38: 3533-3545

63 Fan Y, Nikitina T, Morin-Kensicki EM, Zhao J, Magnuson TR, Woodcock CL, Skoultchi AI. H1 linker histones are essential for mouse development and affect nucleosome spacing in vivo. Mol Cell Biol, 2003, 23: 4559-4572

64 Wierzbicki AT, Jerzmanowski A. Suppression of histone H1 genes in Arabidopsis results in heritable developmental defects and stochastic changes in DNA methylation. Genetics, 2005, 169: 997-1008

65 Rea M, Zheng W, Chen M, Braud C, Bhangu D, Rognan TN, Xiao W. Histone $\mathrm{H} 1$ affects gene imprinting and DNA methylation in Arabidopsis. Plant J, 2012, 71: 776-786

66 Ingouff M, Hamamura Y, GourgueS M, Higashiyama T, Berger F. Distinct dynamics of HISTONE3 variants between the two fertilization products in plants. Curr Biol, 2007, 17: 1032-1037

67 Ingouff M, Rademacher S, Holec S, Soljlc L, Xin N, Readshaw A, Foo SH, Lahouze B, Sprunck S, Berger F. Zygotic resetting of the HISTONE 3 variant repertoire participates in epigenetic reprogram- ming in Arabidopsis. Curr Biol, 2010, 20: 2137-2143

68 van der Heijden GW, Dieker JW, Derijck AAHA, Muller S, Berden JHM, Braat DDM, van der Vlag J, de Boer P. Asymmetry in Histone $\mathrm{H} 3$ variants and lysine methylation between paternal and maternal chromatin of the early mouse zygote. Mech Dev, 2005, 122: 1008-1022

69 Callaini G, Riparbelli MG. Fertilization in Drosophila melanogaster: centrosome inheritance and organization of the first mitotic spindle. Dev Biol, 1996, 176: 199-208

70 Montellier E, Boussouar F, Rousseaux S, Zhang K, Buchou T, Fenaille F, Shiota H, Debernardi A, Hery P, Curtet S, Jamshidikia M, Barral S, Holota H, Bergon A, Lopez F, Guardiola P, Pernet K, Imbert J, Petosa C, Tan MJ, Zhao YM, Gerard M, Khochbin S. Chromatin-to-nucleoprotamine transition is controlled by the histone H2B variant TH2B. Genes Dev, 2013, 27: 1680-1692

71 Allis CD, Glover CV, Bowen JK, Gorovsky MA. Histone variants specific to the transcriptionally active, amitotically dividing macronucleus of the unicellular eucaryote, Tetrahymena thermophila. Cell, 1980, 20: 609-617

72 Santisteban MS, Kalashnikova T, Smith MM. Histone H2A.Z regulates transcription and is partially redundant with nucleosome remodeling complexes. Cell, 2000, 103: 411-422

73 Adam M, Robert F, Larochelle M, Gaudreau L. H2A.Z is required for global chromatin integrity and for recruitment of RNA polymerase II under specific conditions. Mol Cell Biol, 2001, 21: 6270-6279

74 Meneghini MD, Wu M, Madhani HD. Conserved histone variant H2A.Z protects euchromatin from the ectopic spread of silent heterochromatin. Cell, 2003, 112: 725-736

75 Hardy S, Jacques PE, Gevry N, Forest A, Fortin ME, Laflamme L, Gaudreau L, Robert F. The euchromatic and heterochromatic landscapes are shaped by antagonizing effects of transcription on H2A.Z deposition. PLoS Genet, 2009, 5: e1000687

76 Santisteban MS, Hang MD, Smith MM. Histone variant H2A.Z and RNA polymerase II transcription elongation. Mol Cell Biol, 2011, 31: 1848-1860

77 Swaminathan J, Baxter EM, Corces VG. The role of histone H2Av variant replacement and histone $\mathrm{H} 4$ acetylation in the establishment of Drosophila heterochromatin. Genes Dev, 2005, 19: 65-76

78 Dhillon N, Kamakaka RT. A histone variant, Htzlp, and a Sirlp-like protein, Esc2p, mediate silencing at HMR. Mol Cell, 2000, 6: 769-780

79 Fan JY, Rangasamy D, Luger K, Tremethick DJ. H2A.Z alters the nucleosome surface to promote HP1 alpha-mediated chromatin fiber folding. Mol Cell, 2004, 16: 655-661

80 Leach TJ, Mazzeo M, Chotkowski HL, Madigan JP, Wotring MG, Glaser RL. Histone H2A.Z is widely but nonrandomly distributed in chromosomes of Drosophila melanogaster. J Biol Chem, 2000, 275 : 23267-23272

81 Raisner RM, Hartley PD, Meneghini MD, Bao MZ, Liu CL, Schreiber SL, Rando OJ, Madhani HD. Histone variant H2A.Z marks the $5^{\prime}$ ends of both active and inactive genes in euchromatin. Cell, 2008, 134: 188-188

82 Barski A, Cuddapah S, Cui KR, Roh TY, Schones DE, Wang ZB, Wei G, Chepelev I, Zhao KJ. High-resolution profiling of histone methylations in the human genome. Cell, 2007, 129: 823-837

83 Fan JY, Gordon F, Luger K, Hansen JC, Tremethick DJ. The essential histone variant H2A.Z regulates the equilibrium between different chromatin conformational states. Nat Struct Biol, 2002, 9: 172-176

84 Coleman-Derr D, Zilberman D. Deposition of histone variant H2A.Z within gene bodies regulates responsive genes. PLoS Genet, 2012, 8: e1002988

85 Dion MF, Kaplan T, Kim M, Buratowski S, Friedman N, Rando OJ. Dynamics of replication-independent histone turnover in budding yeast. Science, 2007, 315: 1405-1408

86 Rufiange A, Jacques PE, Bhat W, Robert F, Nourani A. Genome-wide replication-independent histone H3 exchange occurs predominantly at promoters and implicates H3K56 acetylation and Asf1. Mol Cell, 2007, 27: 393-405

87 Mito Y, Henikoff JG, Henikoff S. Genome-scale profiling of histone 
H3.3 replacement patterns. Nat Genet, 2005, 37: 1090-1097

88 Stroud H, Otero S, Desvoyes B, Ramirez-Parra E, Jacobsen SE, Gutierrez C. Genome-wide analysis of histone H3.1 and H3.3 variants in Arabidopsis thaliana. Proc Natl Acad Sci USA, 2012, 109: 5370-5375

89 Kraushaar DC, Jin WF, Maunakea A, Abraham B, Ha M, Zhao KJ. Genome-wide incorporation dynamics reveal distinct categories of turnover for the histone variant H3.3. Genome Biol, 2013, 14: R121

90 Rogakou EP, Pilch DR, Orr AH, Ivanova VS, Bonner WM. DNA double-stranded breaks induce histone $\mathrm{H} 2 \mathrm{AX}$ phosphorylation on serine 139. J Biol Chem, 1998, 273: 5858-5868

91 Stiff T, O'Driscoll M, Rief N, Iwabuchi K, Lobrich M, Jeggo PA. ATM and DNA-PK function redundantly to phosphorylate H2AX after exposure to ionizing radiation. Cancer Res, 2004, 64: 2390-2396

92 Stiff T, Walker SA, Cerosaletti K, Goodarzi AA, Petermann E, Concannon P, O'Driscoll M, Jeggo PA. ATR-dependent phosphorylation and activation of ATM in response to UV treatment or replication fork stalling. EMBO J, 2006, 25: 5775-5782

93 Bonner WM, Redon CE, Dickey JS, Nakamura AJ, Sedelnikova OA, Solier S, Pommier Y. GammaH2AX and cancer. Nat Rev Cancer, 2008, 8: 957-967

94 Stucki M, Clapperton JA, Mohammad D, Yaffe MB, Smerdon SJ, Jackson SP. MDC1 directly binds phosphorylated histone H2AX to regulate cellular responses to DNA double-strand breaks. Cell, 2005, 123: $1213-1226$

$95 \mathrm{Wu} \mathrm{L}$, Luo K, Lou Z, Chen J. MDC1 regulates intra-S-phase checkpoint by targeting NBS1 to DNA double-strand breaks. Proc Natl Acad Sci USA, 2008, 105: 11200-11205

96 Melander F, Bekker-Jensen S, Falck J, Bartek J, Mailand N, Lukas J. Phosphorylation of SDT repeats in the MDC1 $\mathrm{N}$ terminus triggers retention of NBS1 at the DNA damage-modified chromatin. J Cell Biol, 2008, 181: 213-226

97 Lou Z, Minter-Dykhouse K, Franco S, Gostissa M, Rivera MA, Celeste A, Manis JP, van Deursen J, Nussenzweig A, Paull TT, Alt FW, Chen J. MDC1 maintains genomic stability by participating in the amplification of ATM-dependent DNA damage signals. Mol Cell, 2006, 21: 187-200

98 van Attikum H, Fritsch O, Hohn B, Gasser SM. Recruitment of the INO80 complex by H2A phosphorylation links ATP-dependent chromatin remodeling with DNA double-strand break repair. Cell, 2004, 119: 777-788

99 van Attikum H, Fritsch O, Gasser SM. Distinct roles for SWR1 and INO80 chromatin remodeling complexes at chromosomal double-strand breaks. EMBO J, 2007, 26: 4113-4125

100 Ikura T, Tashiro S, Kakino A, Shima H, Jacob N, Amunugama R, Yoder K, Izumi S, Kuraoka I, Tanaka K, Kimura H, Ikura M, Nishikubo S, Ito T, Muto A, Miyagawa K, Takeda S, Fishel R, Igarashi K, Kamiya K. DNA damage-dependent acetylation and ubiquitination of H2AX enhances chromatin dynamics. Mol Cell Biol, 2007, 27: 7028-7040

101 Nazarov IB, Smirnova AN, Krutilina RI, Svetlova MP, Solovjeva LV, Nikiforov AA, Oei SL, Zalenskaya IA, Yau PM, Bradbury EM, Tomilin NV. Dephosphorylation of histone gamma-H2AX during repair of DNA double-strand breaks in mammalian cells and its inhibition by calyculin A. Radiat Res, 2003, 160: 309-317

102 Keogh MC, Kim JA, Downey M, Fillingham J, Chowdhury D, Harrison JC, Onishi M, Datta N, Galicia S, Emili A, Lieberman J, Shen X, Buratowski S, Haber JE, Durocher D, Greenblatt JF, Krogan NJ. A phosphatase complex that dephosphorylates gammaH2AX regulates DNA damage checkpoint recovery. Nature, 2006, 439: 497-501

103 Chowdhury D, Keogh MC, Ishii H, Peterson CL, Buratowski S, Lieberman J. gamma-H2AX dephosphorylation by protein phosphatase 2A facilitates DNA double-strand break repair. Mol Cell, 2005, 20: 801-809

104 Tsukuda T, Fleming AB, Nickoloff JA, Osley MA. Chromatin remodelling at a DNA double-strand break site in Saccharomyces cerevisiae. Nature, 2005, 438: 379-383

105 Berkovich E, Monnat RJ, Jr., Kastan MB. Roles of ATM and NBS1 in chromatin structure modulation and DNA double-strand break repair. Nat Cell Biol, 2007, 9: 683-690

106 Heo K, Kim H, Choi SH, Choi J, Kim K, Gu J, Lieber MR, Yang AS, An W. FACT-mediated exchange of histone variant H2AX regulated by phosphorylation of $\mathrm{H} 2 \mathrm{AX}$ and ADP-ribosylation of Spt16. Mol Cell, 2008, 30: 86-97

107 Xu Y, Ayrapetov MK, Xu C, Gursoy-Yuzugullu O, Hu Y, Price BD. Histone H2A.Z controls a critical chromatin remodeling step required for DNA double-strand break repair. Mol Cell, 2012, 48: 723-733

108 Xu Y, Sun Y, Jiang X, Ayrapetov MK, Moskwa P, Yang S, Weinstock DM, Price BD. The p400 ATPase regulates nucleosome stability and chromatin ubiquitination during DNA repair. J Cell Biol, 2010, 191: 31-43

109 Sun Y, Jiang X, Xu Y, Ayrapetov MK, Moreau LA, Whetstine JR, Price BD. Histone H3 methylation links DNA damage detection to activation of the tumour suppressor Tip60. Nat Cell Biol, 2009, 11: 1376-1382

110 Murr R, Loizou JI, Yang YG, Cuenin C, Li H, Wang ZQ, Herceg Z. Histone acetylation by Trrap-Tip60 modulates loading of repair proteins and repair of DNA double-strand breaks. Nat Cell Biol, 2006, 8: 91-99

111 Pierce AJ, Jasin M. Measuring recombination proficiency in mouse embryonic stem cells. Methods Mol Biol, 2005, 291: 373-384

112 Vermeulen M, Timmers HTM. Grasping trimethylation of histone H3 at lysine 4. Epigenomics, 2010, 2: 395-406

113 Papamichos-Chronakis M, Watanabe S, Rando OJ, Peterson CL. Global regulation of H2A.Z localization by the INO80 chromatinremodeling enzyme is essential for genome integrity. Cell, 2011, 144: 200-213

114 Kumar SV, Wigge PA. H2A.Z-containing nucleosomes mediate the thermosensory response in Arabidopsis. Cell, 2010, 140: 136-147

115 Smith AP, Jain A, Deal RB, Nagarajan VK, Poling MD, Raghothama $\mathrm{KG}$, Meagher RB. Histone H2A.Z regulates the expression of several classes of phosphate starvation response genes but not as a transcriptional activator. Plant Physiol, 2010, 152: 217-225

116 March-Diaz R, Garcia-Dominguez M, Lozano-Juste J, Leon J, Florencio FJ, Reyes JC. Histone H2A.Z and homologues of components of the SWR1 complex are required to control immunity in Arabidopsis. Plant J, 2008, 53: 475-487

117 Tamada Y, Yun JY, Woo SC, Amasino RM. ARABIDOPSIS TRITHORAX-RELATED7 is required for methylation of lysine 4 of histone $\mathrm{H} 3$ and for transcriptional activation of FLOWERING LOCUS C. Plant Cell, 2009, 21: 3257-3269

118 Lazaro A, Gomez-Zambrano A, Lopez-Gonzalez L, Pineiro M, Jarillo JA. Mutations in the Arabidopsis SWC6 gene, encoding a component of the SWR1 chromatin remodelling complex, accelerate flowering time and alter leaf and flower development. J Exp Bot, 2008, 59: 653-666

119 Deal RB, Topp CN, McKinney EC, Meagher RB. Repression of flowering in Arabidopsis requires activation of FLOWERING LOCUS C expression by the histone variant H2A.Z. Plant Cell, 2007, 19: 74-83

$120 \mathrm{He}$ YH. Control of the transition to flowering by chromatin modifications. Mol Plant, 2009, 2: 554-564

121 March-Diaz R, Reyes JC. The beauty of being a variant: H2A.Z and the SWR1 complex in plants. Mol Plant, 2009, 2: 565-577

122 Qin Y, Zhao L, Skaggs MI, Andreuzza S, Tsukamoto T, Panoli A, Wallace KN, Smith S, Siddiqi I, Yang Z, Yadegari R, Palanivelu R. ACTIN-RELATED PROTEIN6 regulates female meiosis by modulating meiotic gene expression in Arabidopsis. Plant Cell, 2014, 26: $1612-1628$

123 Shu H, Nakamura M, Siretskiy A, Borghi L, Moraes I, Wildhaber T, Gruissem W, Hennig L. Arabidopsis replacement histone variant H3.3 occupies promoters of regulated genes. Genome Biol, 2014, 15: 2014-2015

Open Access This article is distributed under the terms of the Creative Commons Attribution License which permits any use, distribution, and reproduction in any medium, provided the original author(s) and source are credited. 